manageable vascular surgery atlas. It would be a useful addition to any resident's or surgeor's library.

CRAIG McBRAYER, DO

Assistant Professor of Surgery

Chicago College of Osteopathic

Medicine

Chicago, Ill

\section{Logan Turner's Diseases of the nose, throat and ear}

Edited by A.G.D. Maran. Ed 10. Pp 456, with illus. PSG Publishing $\mathrm{Co}$, Inc, 545 Great Rd, PO Box 6, Littleton, MA 01460, $1988, \$ 29.50$ (paper).

Divided into four sections-- the nose; head and neck; the ear; and and pediatrics-this book covers otolaryngology concisely.

The areas comprised here, such as salivary gland tumors, deal with surgical anatomy along with various medical and surgical conditions involving the salivary glands. Types of tumors concerning these structures are discussed as well as postsurgical complications.

Of particular interest, the chapter on pediatric otolaryngology nicely covers the primary concerns of tonsils and adenoids; laryngeal stridor; intubation and tracheostomy; congenital defects of the larynx (subglottic stenosis); head and neck tumors; hearing problems; and acute ear and mastoid infections.

Although DeWeese and Saunder's Textbook of otolaryngology is the preferred text for residents, the book in question presents a good general overview. It would benefit the medical student on an ear, nose and throat rotation, first year otolaryngology residents, and serve as a general reference for the general practitioner.

\section{JOHN ALTER, DO}

Pontiac, Mich

\section{Computed cranial \& spinal imaging: A practical introduction}

By John M. Stevens, Alan R. Valentine, and Brian E. Kendall. Pp 248, with illus. Williams \& Wilkins, 428 E Preston St, Baltimore, 21202, 1988, $\$ 44.95$.

Computed axial tomography (CT) and magnetic resonance imaging (MRI) are modalities readily available in the United States and routinely used in medicine. The fundamentals of these imaging applications, while basic to radiology, are often overlooked in a primary care curriculum. This book attempts to provide these basics in an introductory text. The first chapters deal with the physical principles of these modalities. While brief, these initial chapters adequately hit the highlights.

Those pages devoted to anatomy, especially its functional aspects, are much too involved and inappropriate for an introductory text. Furthermore, this subject seems out of place in a book dedicated to imaging. Many discussed structures are distinctly beyond the resolving power of these imaging modalities. Several line drawings included here do not directly correlate to MR or CT images, which markedly detracts from their usefulness.

The remaining sections encompass disease entities by presenting brief descriptions and representative images, primarily CT studies. Generally these images are of average quality; however, some serve as suboptimal examples. In particular, one dealing with multiple sclerosis was mislabeled and upside down.

Overall Computed cranial \& spinal imaging: A practical introduction attempts to provide the nonradiologist in training with some basics of CT and MRI of the brain and spine. In that context it does so adequately. Nonetheless, I would not recommend it to anyone with more than a passing interest in these two very important imaging modalities concerning the central nervous system.

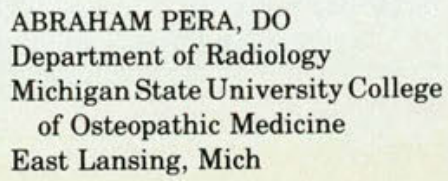

Books received

\section{Anatomy}

Oxford textbook of functional anatomy: Thorax and abdomen, Vol 2. By Pamela C.B. MacKinnon and John F. Morris; pp 138, with illus; Oxford University Press, 200 Madison Ave, New York, 10016, 1988 , $\$ 24.95$ (paper).

\section{Immunology}

Immunology essentials of surgical practice. Edited by Luis H. Toledo-Pereyra; pp 421, with illus; PSG Publishing Co, Inc, 545 Great Rd, PO Box 6, Littleton, MA $01460,1988, \$ 69.50$.

\section{Of general interest}

The reverse effect: How vitamins and minerals promote health and cause disease. By Walter A. Heiby; pp 1198, with illus; MediScience Publishers, PO Box 256, Deerfield, IL $60015,1988, \$ 59.50$.

\section{Orthopedics}

Foot function: A programmed text. By Michael O. Seibel; pp 264, with illus; Williams \& Wilkins, 428 East Preston St, Baltimore, 21202, 1988, $\$ 39.50$ (paper).

\section{Osteopathic manipulative treatment}

Manual medicine therapy. By Werner Schneider, Jiři Dvořák, and Thomas Tritschler. Translated and edited by Wolfgang G. Gilliar, DO, and Philip E. Greenman, DO; pp 148, with illus; Thieme Medical Publishers, Inc, 381 Park Ave South, New York, 10016, 1988, $\$ 59.00$.

\section{Practice management}

Acquiring and enhancing physicians practices: Strategic issues and implementation guidelines for hospitals and physicians. By Steven Portnoy, Ross E. Stromberg, and Philip A. Newbold; pp 146, with illus; American Hospital Publishing, Inc, 211 East Chicago Ave, Chicago, 60611, $1988, \$ 35.00$ (paper) $\$ 28.00$ AHA members.

Fundamentals of private practice in physical therapy. By Mark A. Brimer; pp 224, with illus; Charles C Thomas•Publishers, 2600 South First St, Springfield, IL 62794$9265, \$ 29.75$.

\section{Sports medicine}

The 'E' factor: The secrets of new tech training and fitness for the winning edge. By Bob Goldman, DO, and Ronald Klatz, DO; pp 575, with illus; William Morrow \& Co, Inc, 105 Madison Ave, New York, $10016,1988, \$ 24.95$. 


\section{Coming in ...}

\section{THE DO}

Treat yourself . . . to US travel, when the November issue of The DO takes a look at some of the most unique vacation spots in the country.

Featured in the issue is a guide to attractions located in many of the cities where upcoming CME meetings will be held. Also included is a guide to outdoor adventure travel and an explanation of the often confusing maze of airfare rates and frequent flier programs. Even armchair travelers might be inspired to get up and go!

\section{JAOA}

The November issue will be the annual report on osteopathic medical education (1987-88). It will feature articles on accreditation, undergraduate and postdoctoral education, and continuing medical education.

\section{AMERICAN ACADEMY OF OSTEOPATHY 1989 INTERNATIONAL SYMPOSIUM}

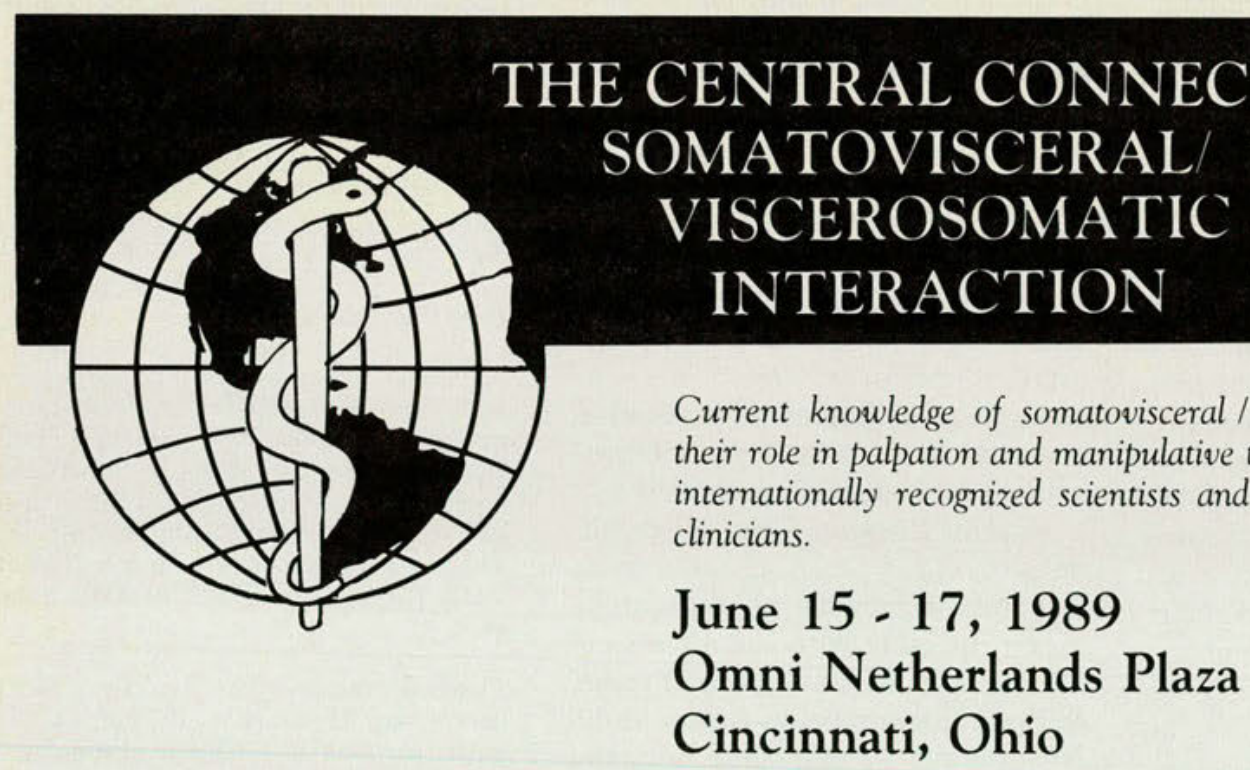

Program Chairman, Michael M. Patterson, PhD $\bullet$ Co-Chairman, John N. Howell, PhD

For more information, contact: Vicki E. Dyson, Executive Director, P.O. Box 750, Newark, Ohio 43055. (614) 349-8701 


\section{Allergy Relief}

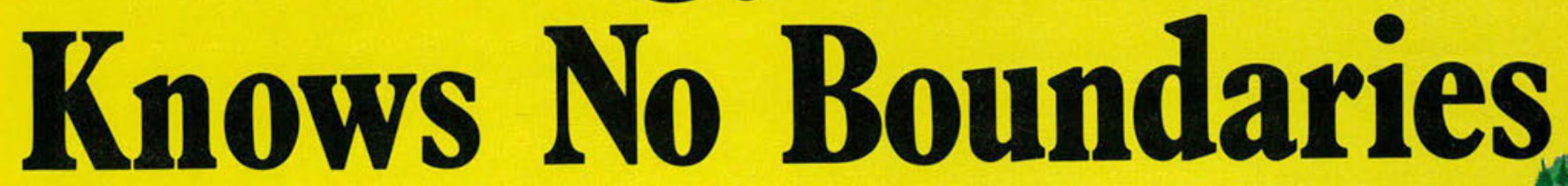

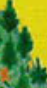
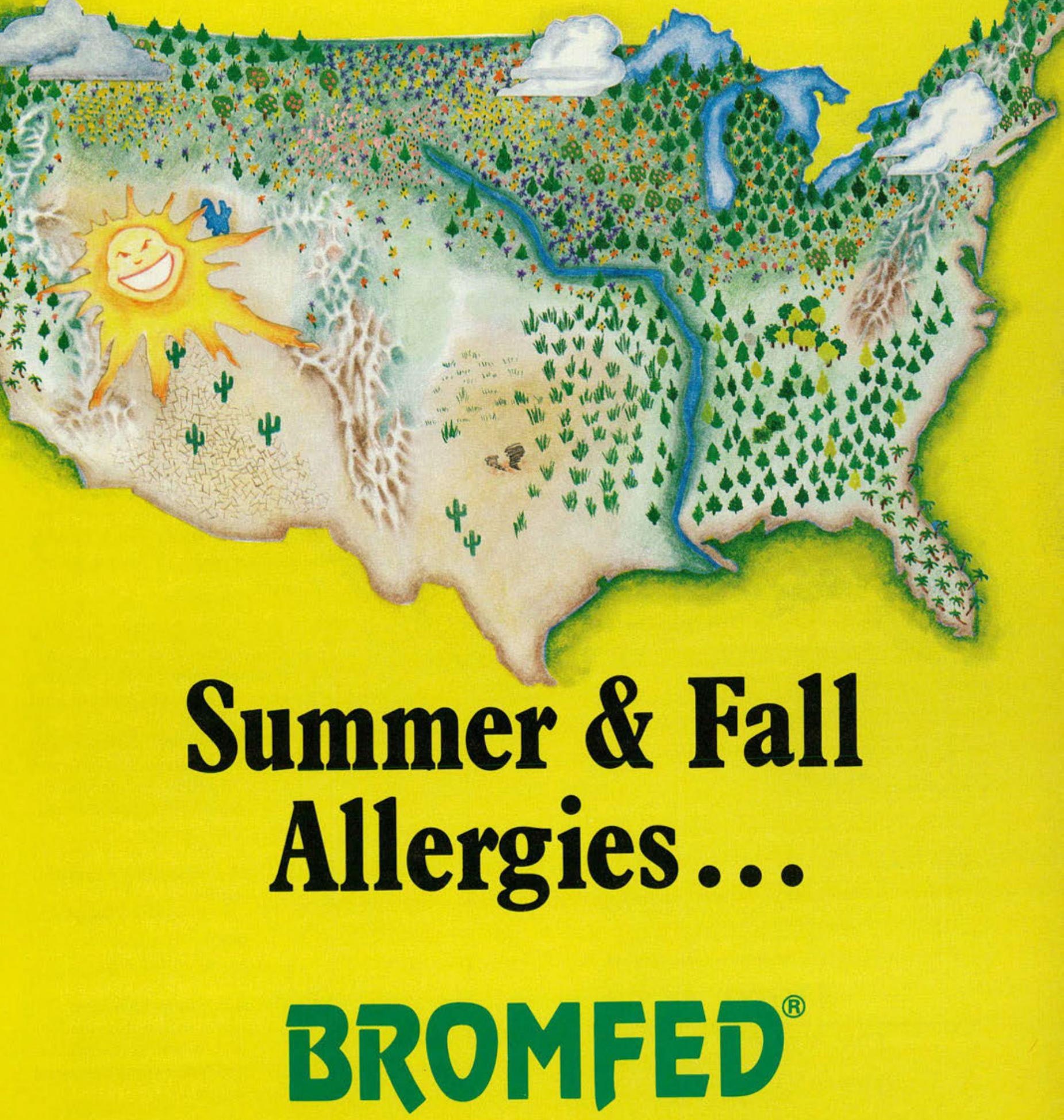